\title{
Realism and abstractionism in Otakar Zich's Theory of dramatic art and Samuel Beckett's experimental dramatics
}

\author{
Herta Schmid
}

In his book Estetika dramatického uměni Teoretická dramaturgie (1931; Aesthetics of Dramatic Art A Theoretical Dramaturgy) Zich maintains - in opposition to Richard Wagner's theory of the Gesamtkunstwerk wherein all arts are equally entitled - that in the dramatic theatre the actor's art must dominate over all the other arts. Jan Mukařovský, on the other hand, differentiates between drama as an autonomous verbal work and as a component of the theatrical performance where it has to compete with the other arts for structural dominance.

In this piece I tackle the question where to place Samuel Beckett, one of the classical authors of modern drama, within this controversy between those two Prague theoreticians. I regard Beckett's Act I: A mime for one player, Act II: A mime for two players and Come and Go: A dramaticule as an experimental series, in which the author demonstrates the formal-structural and semantic potentials of two texts without verbal speech and one text with verbal speech. By creating in his "mutes" first a monologue situation and then a dialogic situation, Beckett makes us aware of a leak or zero-position in their structures, caused by the lack of speech. As a result of the zero-position, the percipient's efforts to find out the total sense remain unsatisfactory.

Otakar Zich as well as Jan Mukařovský differentiate between the author as a real, psychophysical personality on the one hand and the central subject within a work of art on the other. The real author remains out of consideration in a structural analysis where the central subject is an imaginary point from where the whole structure becomes visible. In my contribution I therefore prefer the expression "abstract author" in order to hint at the fact that the real author, although being the producer of the work, is not necessarily able to analyse what he or she has produced. Yet in building his experimental series Beckett seems to have become aware of the abstract author's central point, which changes in each of the three short plays. 
When Otakar Zich's above-mentioned opus magnum was first published in 1931, it was met with praise as well as criticism. While many appreciated the systematic construction of his theory and the precise definition of concepts, his main thesis, according to which dramatic art must necessarily be realistic, i.e. a representation of a recognizable objective world, was met with severe criticism. During the early decades of the twentieth century many artists of the avant-garde favoured experiments with abstraction in the sense of non-objective art even in literature. The realism of the nineteenth century had lost its attraction. Although progressive theatre directors and such important theoreticians of the Prague School as Jan Mukařovský and Jiří Veltruský recognized that in some aspects Zich's theory paved the way for avant-garde art, his name has nonetheless been associated with "old-fashioned taste," until this day.

In what follows I will try to demonstrate that Zich's conception of realism does indeed build some bridges to abstraction. My case studies are three short plays of the classical modernist of the twentieth century, Samuel Beckett: Act Without Words I: A Mime for One Player, followed by Act Without Words II: A Mime for Two Players (both written in 1956) and Come and Go: A Dramaticule (1965). I will first show the systematic relation of Zich's notion of "dramatic art" to "realism" and "abstractionism." This part will be followed by an explanation of Mukařovskýs and Veltruskýs critical views on Zich. The final part will provide an analysis of the three short plays with regard to Beckett's handling of realism and abstraction.

\section{Otakar Zich's definition of dramatic art}

Zich sees in art a means of man's self-knowledge in the tradition of "Know yourself!," the ancient Greek motto from Delphi. Dramatic art obeys that order by its way of representing the human being. This task implies a fundamental realism in the sense of model and prototype. The prototype of realistic representation is for Zich man as a social, speaking and acting being. The attribute "social" implies that human beings should speak and act with one another. Therefore, art may not represent a naturalistic copy of people often isolated in real life but rather create an image of the idea of mankind.

Dramatic art deserves the attribute "social" when presenting at least two living actors on stage who are speaking to each other and acting with each other. Two is Zich's minimal demand for the number of actors in drama. Speaking to each other is based on the dialogical system of language, where one replica is paired with a counter-replica; acting with or, more preferably, against each other relies on action and reaction, which constitutes the twofold action-chain in a drama and forms the composition of the whole work. Yet the pair of actors on stage adds a third component, namely the relationship between their bodies. This third component is essential for Zich's full definition of dramatic art.

From this it follows that dramatic art needs written drama insofar as it uses the dialogical system of language, where replicas and counter-replicas carry on the actionreaction chain between two forces. The art of the actor(s) is necessary for the acoustic 
realization of the written dialogue and the optical realization of the outer side of the action-reaction. One might therefore say that the actor's art is in service of the author's art, which had indeed been the pre-valent opinion from Aristotle's time until the nineteenth century. Zich, however, reverses the traditional relationship between author and actor: it is the author who is in service of the actor. The written drama is not autonomous, it needs completion by the actors on stage. Zich views the relation between actor and author as a mutual completion: neither can exist without the other.

Zich justifies his provocative thesis by a psychological argument which states that visual sensual perceptions are more important for the human being than auditory ones. The actor's optical performances - like facial mimics, gesticulations of head and limbs, proxemics of the whole body perceived visually by the spectator - have a stronger stimulating effect on the spectator's inner motoric than the vocal sounds of the dialogue pronounced by the actors. The stronger motoric effect of the visual perceptions in turn calls forth associative memories of the spectator's own actions which, as Zich thinks, enables the spectator to understand the semantic, sensually not perceivable side of the represented actions. The Prague structuralists, however, rejected Zich's psychologism. Yet in another aspect both Mukařovský and Veltruský owe to him a theoretical account that will prove to be especially helpful in my analysis of Beckett's two mimes which are highly abstractive (and in a way "forbidden" by Zich). The first play, Act I: A Mime for One Player has no speech and presents only one instead of the two actors demanded by Zich, while Act II: A Mime for Tiwo Players adds the second actor half but (just like Act I) does not follow Zich's demand for speech.

According to Zich, Beckett's reductions of components necessary for the construction of a dramatic work would exclude the mimes from the very notion of dramatic art. Zich uses abstraction as a device of theoretical thinking, which is why I prefer the term abstractionism. At the base of Zich's abstractionism lies the notion of structure. Any structural analysis examines the components that enter the systematic definition of a special art. Just like his critical successors of the Prague School, Otakar Zich presupposes a hierarchic relationship between the components in a structure coined by the dominant component.

Using a kind of epistemological experiment, Zich abstracts from the semantics of dialogical speech by imagining a theatre performance wherein the actors speak an unknown language. In this experiment, the audible side of the dialogues and the visual corporal movements of the actors come to thee fore. Thanks to their stronger motoric, the movements dominate the audible side with the two actors' bodies appearing as "energetic centres" in the "energetic field" of the stage. The paths of the movements appear as "energetic curves," which may parallel each other, run away from each other or intersect. The result of the energetic relations between the bodies is an action-reaction-pattern which reappears in the relations between the dialogical replicas. It also influences the relationship between the constitutive parts of the total dramatic action in terms of their external aspects. Zich's discovery of the energetic forces on stage and their dynamic relations was very much approved of by Mukařovský and Veltruský, although both criticised his psychologism and his method of defining the dramatic structure. 


\section{The structuralists' critique of Otakar Zich's method of defining the dramatic structure}

The critique sets in at the concept of an art's material. All possibilities of building a structure are latently inherent in the specifics of the material. Artistic structures can be complex when using the materials of different arts, or simple when only one material is used. By the integration into a complex structure, the simple structure becomes subdued to the dominant of the complex structure. It loses its own dominant and adapts itself, as far as its material permits, to the new dominant. Compared to its previous, isolated simple constitution, under the new dominant the simple structure appears as deformed, fragmentary and in need of completion. "Fragmentary" and "in need of completion" are attributes applied by Zich to the written drama: it needs completion by the complex dramatic art, the dominant of which are the actors as dynamic "energetic centres."

From the viewpoint of the Prague structuralists Zich's comparative procedure is inacceptable. As a simple structure using only verbal material, written drama needs completion just as little as lyric and epic poetry. As in those two genres, written drama can insert itself into the complex structure of dramatic theatrical art, but its deformation under the impact of the dominance of the actors says nothing about the structure of written drama in isolation, which has a different dominant. Zich's thesis about the written drama being "in need of completion" thus loses its justification. Written drama as an autonomous poetic genre has the kind of dramatic qualities which is inherent in its homogeneous verbal material.

For the sake of analysing the specific dramatic qualities of written drama Mukařovský and Veltruský reconsider two communicative axes discussed also by Zich but evaluated differently by him. One of these axes runs between the partners of the dialogue, the other one between the abstract author and the reader. The monological authorreader-axis is functionally constitutive for the dialogical axis because it founds that axis. One can imagine the founding axis as a vertical line crossed by the founded horizontal line along which the partners of the dialogue are situated. The vertical line is expressed by the so-called stage directions - more appropriate would be the term "author's directions." These directions tolerate extreme reduction up to the mere names of the dialogue partners but they can never be entirely absent altogether, for otherwise there would be no literary drama but a dialogical text like in Plato's or Philipp Melanchthon's dialogues. The dialogue, on the other hand, may be lacking in a dramatic text, as is the case in Beckett's Act I and Act II. Zich discusses the author's directions under the question of how far linguistic signs are capable of representing concrete, sensually perceptible things. Compared to the concreteness of the actors' bodies on the real stage, the linguistic signs appear necessarily as deficient. Yet the surplus of concreteness in actors and stage objects is superfluous in written drama. From a structuralist vantage point, Zich's evaluation of the functionally constitutive relation between the author's directions and the dialogic text is wrong. Taking up Zich's discussion of the relationship between the two kinds of texts in the 
written drama - author's directions and verbal dialogue - Mukařovský and Veltruský correct his theoretical shortcomings.

If then the comparison between the written text and its appearance in a dramatic performance provides no adequate insight into the true nature of the drama as a literary genre, another kind of comparison remains well possible: the comparison between written dramas themselves. Beckett actually insinuates such a comparison by the sheer fact that he numbers the two mimes: Act I and Act II.

\section{Realism and abstraction in Beckett's short plays}

If we apply Otakar Zich's notion of dramatic realism to the three short plays, the two mimes Act I and Act II would not merit the attributes of either realistic or dramatic owing to their "violations" of Zich's demands, whereas Come and Go, which features three characters who do speak with each other, would fully comply. What will, however, emerge from my analysis is that Act I, although being the least "realistic" in Zich's metric (only one mute player), has the highest degree of dramatic tension while Act II is approaching Zich's kind of "realism" thanks to its second player but it has a lower degree of dramatic tension. The lowest degree has Come and Go, in spite of its full "realism."

Let us, first of all, return to the previously mentioned theory of the two communicative axes in the short plays (always seen from the viewpoint of the reader). When the founded axis (the dialogue) is omitted from the structure of a drama, it leaves a zero position. At the same time, the founding axis comes to the fore, which normally, as in Come and Go where there is no zero position, remains in the background of the reader's attention. The comparison between the three plays shows us that Beckett constructs a series of experiments. The method of the experiments uses two aspects of abstraction, namely abstraction from something and abstraction onto something. The second aspect reveals the zero position in the structure. That is the case in Act I where Beckett undertakes an abstraction from the dialogue and the second partner. The aim is to find out what kind of drama is possible in a structure with such a gaping lacuna. After that, Act II adds the second partner, the lacuna is less gaping but not yet filled up because the two players do not speak. Finally, in Come and Go the lacuna is filled up. Beckett's experimental method gives insight into the laws of drama by first damaging its structure and then repairing it step by step. His method is creative compared to the theoretical one of Otakar Zich's. I attempt to point out the difference by naming Zich's method "abstractionism" and Beckett's method "abstraction" respectively.

\section{Act I: A mime for one player}

The introductory sentences of Beckett's stage direction are: Desert. Dazzling light. The man is flung backwards on stage from right wing. He falls, gets up immediately, dusts himself, turns aside, reflects. Whistle from right wing. 
The relation between the abstract author and the player is shaped in these initial sentences by four functions: 1. The author fixes the dramatic character at a certain place. 2. He calls the dramatic character "the man." 3. He characterises him by physical mobility and psychic qualities like care for his body and his capacity for reflexion. 4 . He contacts the man acoustically. In total, these four functions build up a communication situation between author and reader wherein the sentences represent the object of the communication in the reader's mind. The acoustic contact with the represented man introduces into the vertical author-reader-communication an action-reaction-relation between author and man. Since this internal relation is lying on the same vertical axis as the external author-reader-axis, the acoustic signal (the whistle) also addresses the reader. His attention must focus on the actions and reactions going on between the abstract author and the man.

When we focus on the whistle, we observe the following possibilities of its appearance: the whistle can appear alone or it can precede one or more objects descending from flies, yet it can also follow objects already present. Depending on the man's reactions to whistle and objects, the abstract author too reacts to the man. That means, the author is observing the reactive activities of the man, and likewise he evaluates his activities.

Without any connection to objects, the whistle occurs only in the introduction of the play as quoted above. In the empty desert, the whistle rings from the right side, then from the left side and then again from the left. The man reacts to the first two whistles by an attempt to flee in the direction where the whistle came from. Each time he is flung back. The repetition of the whistle from the left aims evidently at testing the man's capacity for learning by negative experience. That is expressed in the description of the man's behaviour after the second whistle from the left: He reflects, goes towards left wing, hesitates, thinks better of it, halts, turns aside, reflects.

After the introductory phase, there follows a series of single actions-reactions in which the author tests out the reactions of the man to objects descending from flies and pulled up again. The series opens with two objects that are to test the man's value preferences. The first descending object is a little tree that has a single bough and a meagre tuft of palms casting at its foot a circle of shadow; the second is a pair of tailor's scissors. The author sets apparently an alternative between both objects, for he makes the shadow where the man had sat down disappear (The palms close like a parasol, the shadow disappears) when the man takes the scissors in order to trim his nails, in keeping with his care for bodily neatness.

Now follows a lengthy series of objects with an instrumental value or a mixed mentalbodily value. The latter value sticks to a tiny carafe with a huge label inscribed "WATER," the instrumental value to three cubes of different size and a rope with knots to facilitate ascent. The man tries out combinations of the cubes for ascent to the carafe but each time he climbs a bit higher on his "ladder" the carafe is pulled up beyond reach, and the man falls down. So the height of fall grows continuously. Yet when the man tries to climb up the rope, he does not fall because now the rope is let out and deposits him back on the ground. This implies a peripety in the author's attitude toward the man. 
While until then he had let the man climb up ever higher and fall ever deeper, he now lets him stand, sit and finally lie on the ground. In his new positions close and closer to the ground, the man attempts two suicides, the first by forming the rope to a lasso with which to hang himself on the bough, the second by cutting his throat with the tailor's scissors. After the failure of both attempts - the means for suicide disappear in the flies - the man, sitting on a cube, falls for a last time: The big cube is pulled from under him. He falls. Until the end of the play, the man remains motionless lying on the ground.

One can conclude from the negative results of the climbing phases and the phases of suicidal attempts that the author disapproves of the man's guiding values. The question arises whether the play presents any positive value recognized by the author. It seems to me that such a value is inherent in the relations between the tree and the man sitting in its shadow and looking at his hands before the descent of the tailor's scissors. Yet the content of that value will become concrete only in Act II.

The development of the play observed so far shows a segmentation of the actionreaction-relation between author and player where we, focusing on the appearance of the whistle, discover a rising line. In segment I (whistle without objects) the author convinces the man and the reader that flight from the desert either to the left or to the right is impossible. In segment II (whistle, shadow of the tree, tailor's scissor) the man's choice of the scissors shows his prior value (manicure). In segment III (whistle, apparatuses for climbing, carafe with inscription) the author tests out the man's obstinate sticking to his mental-bodily values in spite of the ever more painful defeats (the increasing height of the fall). The line between the three segments forms a half curve rising gradually to a climax. During that half curve the whistle precedes each single descending and ascending object. In segment IV the man, having learned that his highest value object (the carafe) is unreachable, tries out a new method of escaping his situation by the two suicidal attempts. The failure of these attempts marks a descending half curve by their gradually diminishing height of the fall. In segment $\mathrm{V}$, the falling half curve has reached its lowest point (the man lying on the ground). During the second half curve the whistle points at objects already present in the situation.

The segmentation into five parts which show a slowly rising (three segments) and a more rapidly falling (two segments) line is the main feature of the pyramidal composition of classical drama. In Act I Beckett establishes himself as a "classical" dramatist. In addition to its classical form, Act I also satisfies Aristotle's ideal for action in tragedy: the beginning part, not caused by preceding circumstances, should be the necessary or probable cause of the middle part which in its turn causes the final part, not followed by further consequences. This logic becomes apparent in the contrasting ways of the whistle's appearance during the first half curve (the whistle precedes objects needed for climbing to the carafe) and the second half curve (the whistle points to the already-present objects, the lasso and the pair of scissors, which may be used for attempting suicide). Particularly interesting is the compositional reversal of the rope and the tailor's scissors. During the rising half curve of the compositional pyramid (sections I, II, III), the scissors appeared at the beginning of section II, whereas the rope 
appeared only towards the end of section III. In section IV, the rope used for the first suicide attempt precedes the scissors used for the second attempt. This reversal urges the reader to re-read the play backwards, from the end to the start. He or she will then discover the causal chain between all the objects. Another appeal to read the play in the regressive way can be found in the repetition of the whistle from right and left wing between the first and second suicide attempt in section IV. Like in the very beginning of the play, the man reacts by trying to leave and is flung back. Evidently, the author wants him to try out the tailor's scissors for another fruitless suicide attempt. Finally, in section $\mathrm{V}$, when the man is lying motionless on the ground, the whistle announces the (again reversed) re-appearance of the objects that had started the play: at first the carafe, then the bough and then the tuft of palms casting a shadow. The play could start again, had the man not learned his lesson that all his actions were in vain, as the final author's remark makes clear: He [the man] looks at his [empty] hands. CURTAIN.

Although we cannot yet concretize the author's own positive value, we can guess the negative aspect of the man's highest value. It is inherent in the combination of the tiny carafe and its huge inscription "WATER." The capital letters of the inscription are typical of obtrusive advertisement for goods with little content. For this too we will find a parallel in Act II.

\section{Act II: A mime for two players}

I will again quote the initial sentences of the author's directions: This mime should be played on a low and narrow platform at back stage [...] Frieze effect. A is slow, awkward (gags dressing and undressing), absent. B brisk, rapid, precise. The two actions therefore, though $B$ has more to do than A, should have approximately the same duration.

My analysis of this continuation of Act I will focus on the three levels which comprise Otakar Zich's definition of dramatic art: the level of bodily actions, the level of the dialogic replicas and the level of action-reaction. The expression "frieze effect," used in the quoted author's directions, turns the reader's attention to the first level.

1. The level of bodily actions. On a frieze, the arrangements and bodily postures of the presented figures often indicate horizontal movements to the right or left side. When the first movement in Act II sets in, the author himself stresses that dimension: Enter goad right, strictly horizontal. This means also that all movements have to run from right to left.

Dynamic movements of the two players are always framed by static postures. A drawing added to the play's text shows three static positions and the energetic source putting the static bodies into motion: In Position I the players A and B, each hidden in a sack, are lying behind a pile of clothes $\mathrm{C}$ near the right wing in the order CBA. Position II shows the order $\mathrm{CAB}$ in the middle of the platform, Position III the order CBA near the left wing. Thus, pile C lies constantly in front of the players in their sacks, whereas the relation between the sacks changes in the passage from Position I to Position II and 
from Position II to Position III. The impulse never comes from the players but from the goad which darts forward into the sack lying next to him, first into A's sack, then into B's sack, then again into A's sack. In reaction to the stitch (two stitches are always needed as a result of A's inertia), A (wearing shirt) crawls out of his sack, goes to the pile of clothes, puts on trousers, cloak, shoes and hat, carries his own empty and B's full sack to the middle of the platform, undresses (except shirt), lets the clothes fall into an untidy heap in front of his sack, and crawls into his sack. The pattern of B's reaction to the stitch - unlike the slow A, who needed two stitches to crawl out, the brisk B reacts immediately to the stitch - is the same as A's as far as dressing and undressing as well as moving sacks and clothes forward to the left are concerned. What differs are B's neat way of piling up the clothes and the numerous objects he takes from the shirt and cloak pockets. A had taken only two objects from the pockets. When the goad in Position III stitches again into A's sack, the pattern of his reactive movements is considerably shorter than before. I will follow up on this later.

The goad indicates the energy of the action coming from the author, the movements of players $\mathrm{A}$ and $\mathrm{B}$ indicate the energetic reaction. The horizontal dimension of the interchanges between the author's and the players' activities points by contrast back to the vertical dimension in Act $I$ and at the same time marks the zero position of the verbal dialogue.

2. The level of the dialogue replicas. The number of two players and their horizontal arrangement corresponds clearly to a dialogue situation where both partners are equally entitled to replicas and counter-replicas. A and B, however, are never simultaneously outside of their sacks but always in the combination of one player being outside with the other player being inside his respective sack. The situation for the one outside his sack resembles therefore the situation of the single player in Act I. A and B, when outside, are only confronted with three objects, one of them being their own empty sack, the second one the sack filled with the other player, and the third the pile of clothes C. In spite of the dialogically constructed situation a verbal exchange of replicas cannot possibly take place.

3. The level of the twofold action - reaction in the composition. Dramatic action in Otakar Zich's sense of social interaction is not possible in Act II for the very reason that $\mathrm{A}$ and $\mathrm{B}$ are only things for each other. Yet rudiments of social interaction remain. $\mathrm{A}$ and $\mathrm{B}$ outrun each other on the platform as if they were competitors in a race to a common goal. First racer A (from position I, CBA) surpasses racer B (to position II, $\mathrm{CAB}$ ), then racer $\mathrm{B}$ (from position $\mathrm{CAB}$ ) surpasses racer A (to position III, CBA). Position III is the end of the race, the winner is $\mathrm{B}$, but it is not yet the end of the relation between the goad and player A, for the goad stitches again into A's sack, and A crawls out again.

When looking at what has happened until now between the goad and the two players, we notice a race under aggravating rules: 1 . each player stitched by the goad must crawl out of their sack. 2. They must dress the clothes from the pile, take out objects 
from pockets and put them back again. 3. They must drag their own sack and the sack filled with the other racer a bit further to the left and each must set his sack down ahead of the other's sack. 4. They must undress and pile the clothes ahead of their own sack. 5. They must crawl back each into their sack. The whole race is divided into five phases: I. Starting position CBA near the right edge of the platform. II. A moves according to the rules to the middle of the platform. III. Starting position CAB for B. IV. B moves according to the rules towards the left edge of the platform. V. The final position is CBA with the winner B in his sack ahead of A's sack.

The formal arrangement of the race shows that the author's active energy incorporated in the goad has to renew itself continuously, precisely because each racer, according to rule 5, must crawl back into their sack. One might regard the stitches of the goad as the equivalents of the whistle in Act I. Yet unlike Act I, there is no rising and diminishing height of fall, because the five phases take place in the horizontal dimension, as they do on a frieze. The two racers have no height of fall.

What happens when at the end of the race the goad stitches again into A's sack? Evidently, the author expects something better from A than merely the role of a racer, for which A, characterized as slow and awkward, is not the right person in the first place. A's potential for something better seems to be inherent in his characterization as $a b$ sent. If "absent" is to be taken as a short form of "absent-minded," then its meaning is mental absence in corporal presence. The other place of A's mind was already visible during his behaviour as a racer. Each time before dressing and undressing he paused for brooding (broods) and praying (prays). In the final phase after the end of the race, A does not dress. Instead, he remains in his shirt: A crawls out of sack, halts, broods, prays. CURTAIN. He seems to have definitively found the religious-metaphysical dimension adequate to his mind.

By driving A once again out of his sack but letting B lying in his sack, the author suggests to the reader that $\mathrm{B}$, unlike $\mathrm{A}$, has reached his desired goal as the winner in the race. B, whom the initial author's direction characterized as brisk, rapid, precise, is the ideal racer. When we now consider the objects taken out of the shirt and cloak pockets by $\mathrm{B}$, we see that they all fit the born racer, whose only concerns are bodily neatness, fitness and precision: watch, tooth brush, comb, brush, mirror, map, compass and a delicious carrot (swallows with appetite). This long list of B's objects contrasts sharply with A's very short list: a little bottle of pills and a disgusting carrot (spits out disgusted). It becomes evident that $\mathrm{A}$ is the opposite of a racer, so much the more as he interrupts his movements during the race for brooding and praying whereas B uses his halts for gymnastic exercises.

With respect to the players in Act I and Act II, I draw the following conclusion: the characteristic features of the man in Act I are distributed among the contrasting pair of players in Act II in so far as the latter play consists of a race. The man shares with player B the concern for bodily neatness, precision and purposefulness of all movements, and with player A the inclination to reflexion during halts between the movements. Yet by making him use reflexion only in search of mere technical means for reaching his purposes the author leaves him with empty hands in the end. As A uses 
reflexion for praying and as the author leaves him in the end praying, it becomes clear what the man in Act I ought to have done with his hands right from the beginning of that first mime: he should have continued sitting in the tree's shadow praying instead of starting his fatal quest for the worthless carafe. This choice, however, would not have initiated the classical tragedy of a man's fall but would rather have presented a static, idyllic scenery.

With respect to the dramatic tension in Act II, my conclusion is the following: a race is "dramatic" only in the sense of a game in every-day life. Besides, the two racers are not aware of their competitive situation, because they take account of each other only as part in the game in the form of the "heavy sack." Act II therefore has no true dramatic tension, although its two contrasting players would allow for it. The tension which arises in Beckett's second mime is more of a semantic kind. It is inherent in the question of why the pile $\mathrm{C}$ always has to lie in front of the players. The first and third position - CBA close to the right end of the platform, CBA close to the left end of the platform - show B's affinity to the pile C and A's non-affinity to the pile. In the second position - CAB in the middle of the platform - A has imitated B's affinity to pile $\mathrm{C}$ but he corrects his error by position III. As the clothes of pile $\mathrm{C}$ - trousers, cloak, shoes and hat - are typical clothing for a man of the modern society who spends his lifetime in a sportive competition with his fellow man, B is an example of the modern "hero." On the other hand, the praying A, dressed only in his shirt at the end of the play, reminds of the penitent of older times who asks god's forgiveness for having spent his life in an unworthy manner. The author himself suggests the interpretation of A's and B's different relations with pile C as metaphors for different ways of life, when he prescribes that the actions of dressing and undressing (and of course the activities between these actions) should have approximately the same duration. Yet one must not forget the author's use of the word "gags" in his introductory direction: (gags dressing and undressing). "Gag" is a term belonging to the genre of the comedy. A and B appear both like comical types. This sheds a comical, parodist light back on the man in Act I, too.

\section{Come and Go: A Dramaticule}

The introductory author's direction sounds: Sitting centre side by side stage right to left FLO, VI and RU. Very erect, facing front, hands clasped in laps. Silence. I quote the corresponding last direction to let see the change having taken place between the situation at the beginning and the situation at the end: [...] they join hands as follows: VI's right hand with RU's right hand. VI's left hand with FLO's left hand. FLO's right hand with RU's left hand. VI's arms above RU's left arm and FLO's right arm. The three pairs of clasped hands rest on the three laps.

I analyse again the three levels of bodily actions, dialogue and total action - reaction in order to explore how the changes in the relations between hands and arms take place. 
1. The level of bodily actions. The title Come and Go refers to entrance and exit of a character. In the first three scenes of the play, the relation between entrance and exit follows an identical pattern; in the final, fourth scene the pattern is cut short. The beginning of each scene shows the three women sitting side by side, the middle part is marked by the exit of the woman who had been sitting in the centre and the final part is marked by the move of one of the remaining women to the central seat. A sketch added also to this play by Beckett illustrates the dynamic movements within each scene. Scene I: Vlo-Vi-Ru turns by Vi's exit into Flo> - Ru and then by Vi's move to the centre into - Flo-Ru. (The combination of arrow and dash indicates the direction of the move to the vacant centre.) Scene II: Vi-Flo-Ru turns by Flo's exit into Vi $-<\mathrm{Ru}$ and then by Ru's move to the centre into Vi-Ru -. Scene III: Vi-Ru-Vlo turns by Ru's exit into Vi>- Flo and then by Vi's move to the centre into - Vi-Flo. Scene IV: Ru-Vi-Flo. No exit.

The points of exit and re-entrance of the woman who leaves the central seat must always be opposite to one another. The point of re-entrance decides which of the remaining women has to move to the centre, so that the re-entering woman can take her seat. $\mathrm{Vi}$, who exits the first, takes the direction to the right, re-enters on the left and takes Flo's seat, who has moved from left seat to centre, and so forth. These changes cause a swinging movement that runs through all scenes: first from left to right, then from right to left, and then again from left to right. In Scene IV, the swinging movements have reached their aim. Vi has regained here the central seat of Scene I, but Flo and Ru have exchanged places. Were the play to start again, it could now be Ru's task to start the swinging movements inside the scenes instead of Flo. The sense of Flo's and Ru's final changing places will become clear later, when we look at their roles in the dialogue.

Apart from the swinging movements on the bench in full light, there is another movement. The path between exit and re-entrance of each woman lies behind the bench in the dark, so that the reader has to imagine its full course. The three paths form an imaginary pattern which corresponds to the pattern of the crossed arms at the end of the play: Vi's path from right to left is crossed by Flo's path from left to right and Flo's path is crossed by Ru's path from right to left. The correspondence between the two patterns, the smaller one of the arms on the bench, the larger one of the paths behind the bench is, of course, not trivial. It hints at a motoric force set into motion by Vi's first exit, continued by the swinging movements between the remaining two women on the bench and ending in the smaller pattern of the arms, which enables the crosswise pairing of the hands (described in my quote above).

2. The level of the dialogue. For the sake of analysing the dialogic level in this play, I propose new terms which allow to discern between different forms of verbal communication. When all three women are sitting together on the bench, the communicative situation is a "trilogue." After the exit of one woman follows first a "dialogue at a distance" (Ferndialog) across the vacant central seat and then a "dialogue in proximity" (Nahdialog), when one of the remaining women has moved to the central seat. These three types of verbal communication combine to a system of functions. The main functions belong to the trilogue and the two types of dialogues; secondary functions belong 
to the dialogue at a distance on the one hand and the dialogue in proximity, on the other.

The function of the trilogue is to avoid any verbal communication whatsoever. The two types of dialogue share the function of removing the obstacle to communication. So there exists a fundamental opposition between the general forms of trilogue and dialogue. The two types of dialogue each fulfil differently their common function vis- $\grave{a}$ vis the trilogue. This abstract system of functions is realized by a system of speech roles which presents itself immediately in the first scene. Each woman in the initial scene is characterized by a specific speech role.

The trilogue in Scene I presents Flo, Vi and Ru sitting together in silence. Vi, breaking the silence, proposes to speak about their last meeting: "When did we three last meet?" Ru, though not addressed individually, reacts harshly: "Let us not speak." After Vi's exit Flo first opens the dialogue at a distance and then, moving to the central seat, continues in form of a whispered dialogue in proximity. The communicated subject is a fatal change in Vi's life. Both women agree not to tell Vi what has happened to her. The reader is also not informed about Flo's news whispered into Ru's ear. The formal pattern of trilogue, dialogue at a distance and dialogue in proximity is identical in the first three scenes, and the replicas in the dialogues have always the same text. What does change is the replicas in the trilogues.

The speech roles distributed immediately in the first scene among the three women are the following: in the trilogue $\mathrm{Vi}$ provokes $\mathrm{Ru}$ by her wish to speak about the last meeting, $\mathrm{Ru}$ forbids all speech, Flo, keeping silence, is seemingly obedient to Ru's forbidding. Yet, right in the first dialogue at a distance and dialogue in proximity, she takes over the role of breaking Ru's forbidding by means of a subtle manœuver: first, in the dialogue at a distance, she establishes verbal contact with $\mathrm{Ru}$, then, in the dialogue in proximity, she informs Ru about a sad secret concerning Vi that arouses Ru's sympathy for Vi. Ending the dialogue in proximity, Flo engages Ru not to speak to Vi about the secret. Ru imitates Flo's manœuver vis-à-vis Vi in the dialogues of the second scene, $\mathrm{Vi}$ imitates $\mathrm{Ru}$ in the dialogues vis-a-vis Flo in the third scene. At the end of the third scene, Flo knows that her pattern of directing the dialogues was exactly followed by $\mathrm{Ru}$ and Vi.

Since the intention of that pattern was to keep silence about the mischief of each woman in the trilogue, Flo must invent an additional manœuver in order to break Ru's initial forbidding also within the trilogue itself. First, in Scene II, she proposes a way of sitting together from past times. Ru reacts positively and in Scene III she suggests contact through the hands: "Holding hands ... that way." Flo adds: "Dreaming of ... love." So Flo has won Ru to co-operate in restoring the former bodily and emotional proximity. That restoration is the last step to the overcoming of the tabooed theme of what happened during the separation. It is Vi who in Scene IV proposes to speak "of the old days" and of "what came after," holding "hands in the old way." The "old way," leading to the positions of hands and arms described in my quote above, provokes Vi's exclamation: "I can feel the rings." Evidently, the rings have to do with the mischiefs of the women. Rings are a conventional symbol of marriage. The women's 
former dreams "of love", mentioned by Flo in the trilogue of Scene III, have come to emptiness in marriage.

My conclusion about the system of speech roles connected to the system of trilogue and dialogue is the following: Vi's and Ru's speech acts establish a trilogic situation by their oppositional replicas where verbal communication is impossible. Flo's speech acts serve as the means by which communication becomes possible. Her methods of using the two forms of the dialogue in Come and Go are a kind of "friendly" intrigue by which she slowly wins the two opponents as co-operators in the overcoming of the paralysed trilogue.

3. The level of action - reaction. My analyses of the two mimes have shown that an action strives after a goal or, in other words, after a value object. The same holds true for the reaction. The two goals may be identical or different, or even opposite to one another. In Come and Go, the relation between the goals of action and reaction is a sharp opposition. The action-carrier is $\mathrm{Vi}$ who strives after restoring of former intimacy among the three women; the reaction-carrier is $\mathrm{Ru}$ who strives at maintenance of the present estrangement. These two goals are mutually exclusive.

The situation thus described would deliver a fine basis for a traditional drama, containing a quarrel, a fight, a winner and a loser in the end. Yet the speciality of the action-carrier Vi is passivity, expressed by her tacit reaction to Ru's harsh forbidding of any speech. Vi leaves the bench without open protest. A more energetic force is necessary to attain Vi's goal. Flo incarnates that force. Vi and Flo, so to speak, complement each other in respect to the action: Vi utters a wish, Flo realizes that wish. The way of Flo's realization of the action might be called a dialectical one, because $\mathrm{Ru}$, who is opposing speech, must be won over for speech through the means of speech. That is the reason why Flo invents the ruse of the dialogue intruding into the trilogue. Flo is a reincarnation of the traditional comic Gracioso who, like in Lope de Vega's famous comedy Fuente Ovejuna ("The Village Fuente Ovejuna"), invents a form of collective speech that saves the villagers.

Having mentioned the tradition of comedy in Come and Go, two other comic aspects must also be mentioned. One of them is the author's evaluation of the action's goal, the other one is the subtitle "A Dramaticule." As for the author's position, the whole structure of the play resembles a precisely constructed machine which works from the level of bodily actions through the dialogue level up to the total action - reaction level. The rules for the bodily actions, inherent to the title Come and Go, lead, once set to function by Vi's exit to the right, without any further interference of the author to the pre-calculated aim of the joined hands and arms at the end of the play and Flo's final exclamation "I can feel the rings." The difference to Act I and Act II, where the author had to whistle continuously to set the man into motion and to tease A and B by stitches out of their sacks, is obvious.

The subtitle "A Dramaticule" seems to be a neologism composed of "drama" and "ridicule." The second component ridicules the drama so far as the latter claims to present serious matters of human life. In the two mimes such "serious" matters 
are the highest values of the man (the worthless carafe in Act I) and of A and B (the religious metaphysical dimension, the victory in a race in Act II). Here I would like to add that the ancient Greek and Roman genre of the mime could be a satire mocking important institutions like philosophy, politics, religion and, with special pleasure, sex and marriage. Yet in Come and Go, the drama turns out to ridicule in still another aspect. The composition of that play shows a very low dramatic tension thanks to the co-operation of the three women for the common goal of old harmony which starts right after the establishment of the opposition between actioncarrier and reaction-carrier in the first scene. Instead of a rising and falling line of tension like in Act I or a flat line like in Act II, we have a continuously descending line of tension in Come and Go. This way of handling dramatic tension is typical of Čechov, whose four-act plays were criticized by his contemporaries as dull and non-dramatic. There are many other aspects pointing especially to Čechov's Three Sisters, like for instance the use of costume colours (I left this aspect out) and the theme of marriage: one of the sisters is unhappy in marriage, the other is unhappy because she is not married, and the third "dreams" of love in marriage in the unreachable Moscow.

The reference to the Russian dramatist's play may explain why Ru and Flo have to exchange positions at the end of Come and Go. Ru, having taken Flo's initial seat on the left, could start trilogues and dialogues in which the three women would lament over their scattered hopes for marriage and love - like the young women in Three Sisters.

My conclusion concerning Beckett's method of first abstracting the dialogic level from the structure of a drama and then re-adding that level step by step is the following: he lets us see that drama needs the verbal dialogue for full sense of all levels. He also convinces us that dramatic theatre needs the written drama. What remains doubtful is Zich's view about written drama's need of the theatre. The performance of the three short plays on stage is possible but not necessary. In another respect Zich's findings about dramatic art are, however, partly justified by Beckett's experiments. The bodily level is indeed essential to written drama, but it is not the dominant level. Quite inspiring for further research is Zich's typology of different dramatic tensions. Zich finds these types on the upper level of the total action and on the lower level of the actors' bodies, but he does not extend the typology to the dialogue level. Beckett's creative experiments could help extend Zich's typology to that level. 


\section{Bibliography}

BECKETT, Samuel. 1984. Collected Shorter Plays of Samuel Beckett. London: Faber and Faber, 1984. DROZD, David, Tomáš KAČER and Don SPARLING (eds.). 2016. Theatre theory reader: Prague School writings. Prague: Karolinum Press, 2016.

ZICH, Otakar. 1931. Estetika dramatického umění. Teoretická dramaturgie [Aesthetics of Dramatic Art A Theoretical Dramaturgy]. Praha: Melantrich, 1931. 